\title{
Morfología y citoquímica de cultivos celulares de Aedes aegypti (Diptera: Culicidae) y susceptibilidad a Leishmania panamensis (Kinetoplastida: Trypanosomatidae)
}

\author{
Alfonso Arturo Miranda H. ${ }^{1}$, Ladys Sarmiento ${ }^{1}$, María Leonor Caldas M. ${ }^{1}$, Cristina Zapata ${ }^{2}$ \\ $\&$ Felio Jesús Bello G. ${ }^{3}$ \\ 1. Grupo de Microscopía y Análisis de Imágenes, Instituto Nacional de Salud, Av. Calle 26 No 51-60 Bogotá, Colombia. \\ Fax: 2207700- ext 455; 1sarmiento@ins.gov.co \\ 2. Laboratorio de Entomología, Biología Celular y Genética, Departamento de Ciencias Básicas Universidad de La Salle, \\ Bogotá, Colombia; angzapl@yahoo.com.mx \\ 3. Instituto de Ciencias Básicas, Facultad de Medicina, Universidad del Rosario, Bogotá, Colombia; \\ fbello@urosario.edu.co
}

Recibido 16-I-2007. Corregido 30-VIII-2007. Aceptado 01-X-2007.

\begin{abstract}
Morphology and cytochemistry of Aedes aegypti's cell cultures (Diptera: Culicidae) and susceptibility to Leishmania panamensis (Kinetoplastida: Trypanosomatidae). The first cellular line of Aedes aegypti was developed by Grace in 1966; afterwards, other cellular lines of this species have been generated. These have been used for the study of pathogenic organisms like viruses, bacteria and parasites, which demonstrates their importance in biomedical applications. This research describes, for the first time, some cytochemical characteristics of $A$. aegypti cell cultures, that were infected with (MHOM/CO/87CL412) strain of Leishmania panamensis. A morphological study of the cell culture was also carried out. Maintenance of the cell culture, parasites and infection in vitro were carried out in the Laboratory of Entomology, Cell Biology and Genetics of the Universidad de La Salle. The cell cultures infected with the parasite were maintained in a mixture of mediums Grace/L15, supplemented with $10 \%$ fetal bovine serum (FBS) at pH 6.8 and a temperature of $26^{\circ} \mathrm{C}$, during 3, 6 and 9 post-infection days. After this, these cell cultures were processed through High Resolution Light Microscopy (HRLM) and Transmission Electron Microscopy (TEM) based on standard protocols defined by the Group of Microscopy and Image Analyses of the Instituto Nacional de Salud. Semi-fine slices of $1 \mu \mathrm{m}$ colored with toluidine blue were used for the morphological analysis of the culture, and ultra fine cuts of 60 to $90 \mathrm{~nm}$ stained with uranyl acetate and lead citrate where used for the ultrastructural study. In addition, PAS and peroxidase staining was carried out in cells fixed with methanol. The morphometric study was analyzed with software ImageJ (NIH). In the semi-fine slices, small cells were observed showing fibroblastic appearance $10.84 \pm 2.54 \mu \mathrm{m}$ in length and $5.31 \pm 1.26 \mu \mathrm{m}$ wide; other cells had epithelial appearance with a great peripheral nucleus, voluminous and vacuolated cytoplasm, $23.04 \pm 4,00 \mu \mathrm{m}$ in length and $13.96 \pm 3.70 \mu \mathrm{m}$ wide. These last ones predominated over the ones with fibroblastic appearance. Regarding the PAS coloration, $7.08 \%$ of the cells presented abundant PAS positive cytoplasmatic granules which indicated polysaccharides presence. The peroxidase test gave a negative result. The greatest percentage of infection $(18.90 \%)$ of one total of 101 cells, turned up by day 6 . Some cells analyzed by TEM presented a vacuolated aspect cytoplasm; some contained parasites, other fibrillar material and others were empty. The results indicate that $A$. aegypti cell culture can support the internalization and transformation of the parasite, which demonstrates the capacity that these cell cultures have to be infected with L. panamensis and to maintain the infection for approximately one week. Rev. Biol. Trop. 56 (2): 447-458. Epub 2008 June 30.
\end{abstract}

Key words: periodic acid-schiff, cell cultures, Aedes aegypti, Leishmania panamensis, transmission electron microscopy. 
Desde comienzos del siglo XX los entomólogos han tratado de mantener in vitro células de insecto como una herramienta en diferentes campos de estudio (Lynn 2002). Pero solo hasta 1962 Grace obtuvo la primera línea celular de insecto correspondiente a la polilla Antheraea eucalypti. Actualmente, existen más de 500 líneas celulares establecidas a partir de diversos tejidos de insectos, siendo mayor el número de éstas en dípteros y lepidópteros (Lynn 2001).

La primera línea celular de Aedes aegypti fue establecida por Grace en 1966; posteriormente, se generaron otras líneas celulares de esta misma especie (Bhat y Singh 1969, Varma y Pudney 1969). Desde entonces, diferentes cultivos celulares de mosquitos se han utilizado como sustratos para el aislamiento e identificación de arbovirus. Sin embargo, existe en la actualidad una amplia gama de aplicaciones biotecnológicas (Singh 1972, Sudeep et al. 2005), así como también biomédicas, principalmente en investigaciones con algunas bacterias y parásitos (Syafruddin et al. 1992, Dobson et al. 2002). En esta última línea de acción, es importante resaltar el estudio realizado por Fampa et al. (2003), en el cual se muestra la interacción de ciertas especies de tripanosomátidos monoxenos con líneas celulares de A. albopictus, Anopheles gambiae y Lutzomyia longipalpis. De igual manera, se han realizado infecciones con Trypanosoma brucei en cultivos celulares del mosquito A. gambiae, en donde al parecer, no se disminuye la infectividad del parásito al utilizar estas células como sustrato (Kaminsky et al. 1987).

Con lo descrito en los anteriores antecedentes, se pretende resaltar la importancia que tienen los cultivos celulares de mosquitos, en el mantenimiento y estudio del ciclo biológico de tripanosomátidos, importantes en salud publica. Existen algunos trabajos en donde se reporta la infección de Leishmania en diferentes líneas celulares de macrófagos y células dendríticas (Berens y Marr 1979, Zuluaga y Robledo 2004, Sarmiento et al. 2006), pero son pocas las investigaciones relacionadas con la interacción y maduración del parásito en cultivos celulares de insectos. Recientemente, se ha podido demostrar que los cultivos celulares de L. longipalpis y L. spinicrassa son susceptibles a la infección con L. chagasi y L. braziliensis respectivamente (Miranda et al. 2005, Bello et al. 2005, Zapata et al. 2005).

Existe un primer trabajo de infección con L. donovani en cultivos celulares de A. albopictus, mosquito no vector de este patógeno, en el cual se obtuvieron formas amastigotas del parásito y se logró su mantenimiento en estos sustratos celulares (Dedet y Gaudin 1977). También se realizó un estudio de susceptibilidad a la infección con $L$. chagasi y $L$. braziliensis en una línea celular de $A$. aegypti (Ardila et al. 2005), establecida en Colombia a partir de tejidos embrionarios del mosquito. Los registros de esta investigación mostraron relativamente altos porcentajes de infección con ambas especies de parásitos, siendo mayor los resultados de infección con la especie $L$. braziliensis $(29.8 \%)$, obtenidos durante el día 6 post-infección; razón por la cual los autores concluyeron que estos cultivos celulares son un modelo alternativo in vitro para el estudio de los parásitos mencionados (Muñoz et al. 2005).

En el presente trabajo se describe, por primera vez, algunas características citoquímicas de los cultivos celulares de $A$. aegypti, infectados con L. panamensis; también se realizó un estudio morfológico de las células en cultivos y se reporta el porcentaje de infección de $L$. panamensis en estos sustratos celulares.

\section{MATERIALES Y MÉTODOS}

Cultivos celulares e infección: El mantenimiento de los cultivos celulares, parásitos y la infección in vitro, fueron realizados en el Laboratorio de Entomología, Biología Celular y Genética de la Universidad de La Salle. Los cultivos celulares de $A$. aegypti fueron sembrados en seis placas de petri de $35 \times 10 \mathrm{~mm}$ e infectados con la cepa (MHOM/CO/87CL412) de L. panamensis, suministrada por el laboratorio de parasitología del Instituto Nacional de Salud (INS). Los cultivos celulares, infectados con el parásito, fueron 
mantenidos en una mezcla de medios Grace/L15 suplementados con Suero Fetal Bovino (SFB) al $10 \%$, a un $\mathrm{pH} 6.8$ y una temperatura de $26^{\circ} \mathrm{C}$. En los días 3, 6 y 9 post-infección se retiraron dos placas de petri, se lavaron con solución salina y se les realizó el proceso de fijación. De igual forma, se mantuvieron cultivos celulares del mosquito sin infectar.

Procesamiento de muestras para microscopía electrónica: Se recibieron cultivos celulares con y sin infección. Las muestras fueron procesadas según protocolos estandarizados en el Grupo de Microscopía y Análisis de Imágenes del Instituto Nacional de Salud de la siguiente forma: se fijaron con glutaraldehído al 3\% en buffer fosfato $0.1 \mathrm{M} \mathrm{pH} \mathrm{7.2,} \mathrm{luego,} \mathrm{fueron} \mathrm{lava-}$ das tres veces con buffer fosfato $0.1 \mathrm{M} \mathrm{pH} \mathrm{7.2.}$ Posteriormente, a los cultivos se le realizó una post-fijación con tetróxido de osmio $\left(\mathrm{OsO}_{4}\right)$ al $1 \%$ y fueron lavados con el mismo buffer fosfato mencionado anteriormente. Se realizó el proceso de deshidratación con etanol al 50, 70, $80,95 \%$ y finalmente dos cambios de etanol al $100 \%$. La infiltración fue realizada con cambios en mezclas de alcohol y resina epóxica EpónAraldita en proporciones de 2:1 durante $1 \mathrm{~h}, 1: 1$ durante una hora y dos cambios de resina pura durante $24 \mathrm{~h}$. Para la inclusión de las muestras se utilizó la mezcla de resina Epón-Araldita y se dejó polimerizando a $68{ }^{\circ} \mathrm{C}$ por $48 \mathrm{~h}$.

Posterior al procesamiento de las muestras, se obtuvieron cortes semifinos de $1 \mu \mathrm{m}$ los cuales, fueron coloreados con azul de toluidina para su estudio morfológico. La observación de las muestras fueron realizadas en un microscopio de luz Zeiss Axiophot.

Finalmente, se realizaron cortes ultrafinos de 60 a $90 \mathrm{~nm}$, coloreados con acetato de uranilo y citrato de plomo. Para el estudio ultraestructural, se utilizó un microscopio electrónico de transmisión Zeiss EM 109.

Morfometría celular: La captura de imágenes de las células en los días 3, 6 y 9 post-infección y de las células no infectadas, se realizó por medio de una cámara Sony Hyper HAD CCD-IRIS/RGB adaptada a un microscopio de luz Zeiss Axiophot. Las imágenes digitales de las células no infectadas se analizaron por medio del software de acceso libre ImageJ versión v1.38 (NIH; http://rsb.info.nih.gov/ij) (Rasband 1997-2006). Se realizó un estudio morfométrico en el cual se tuvieron en cuenta los parámetros de largo y ancho de las células derivadas de los cultivos de A. aegypti, sin infección.

Citoquímica: La detección de carbohidratos, se realizó mediante la coloración de PAS (García del Moral 1993). Para esto las laminillas redondas de $12 \mathrm{~mm}$ infectadas con $L$. panamensis fueron fijadas con metanol y oxidadas con ácido periódico al $0.5 \%$. Finalmente se evidenció la presencia de carbohidratos con el reactivo de schiff y se realizó el contraste con hematoxilina de Harris. Las laminillas fueron deshidratadas, pasadas por Xilol y adheridas a una lámina con citoresina. La reacción fue observada en el microscopio de luz Zeiss Axiophot.

Se realizó la detección de peroxidasa por medio de la técnica de Diaminobencidina (García del Moral 1993). Las células de $A$. aegypti cultivadas en laminillas redondas de 12 $\mathrm{mm}$ e infectadas con L. panamensis fueron fijadas con metanol y tratadas con una solución de 3.3'-diaminobenzidina a una concentración de $10 \mathrm{mg}$ en $15 \mathrm{ml}$ de buffer TRIS y $12 \mu \mathrm{lde} \mathrm{H}_{2} \mathrm{O}_{2}$ al 30\%. Después de lavar, deshidratar y pasar por Xilol, la laminilla fue adherida a la lámina con citoresina. La observación fue hecha en un microscopio de luz Zeiss Axiophot.

Análisis estadístico: Los datos fueron analizados en el software Statistix 1.0 para Windows. Se les aplicó la prueba de Anova de una vía y el test de Tukey. Los resultados de la morfología celular, porcentaje de células con gránulos PAS positivo y porcentaje de células con vacuolas PAS positivo, fueron analizados en Microsoft Excel 2002, en donde se obtuvo promedio, desviación estándar y error estándar. 


\section{RESULTADOS}

Morfología: En los cultivos celulares correspondientes a células no infectadas, se observaron dos grupos de células morfológicamente diferentes: uno constituido por células de apariencia fibroblastoide con unas dimensiones de $10.84 \pm 2.54 \mu \mathrm{m}$ de largo y $5.31 \pm 1.26 \mu \mathrm{m}$ de ancho, cuyo citoplasma presentaba algunas vacuolas, como se observa en la Fig. 1. El otro grupo estuvo conformado por células de apariencia epitelioide, de unas dimensiones entre $23.04 \pm 4.00 \mu \mathrm{m}$ de largo y $13.96 \pm 3.70 \mu \mathrm{m}$ de ancho, con un núcleo prominente y citoplasma ocupado por numerosas vacuolas (Fig. 1). Estas últimas predominaron sobre las de apariencia fibroblastoide.

El Cuadro 1 nos muestra el promedio del tamaño celular (longitud y amplitud) de las dos morfologías celulares encontradas.

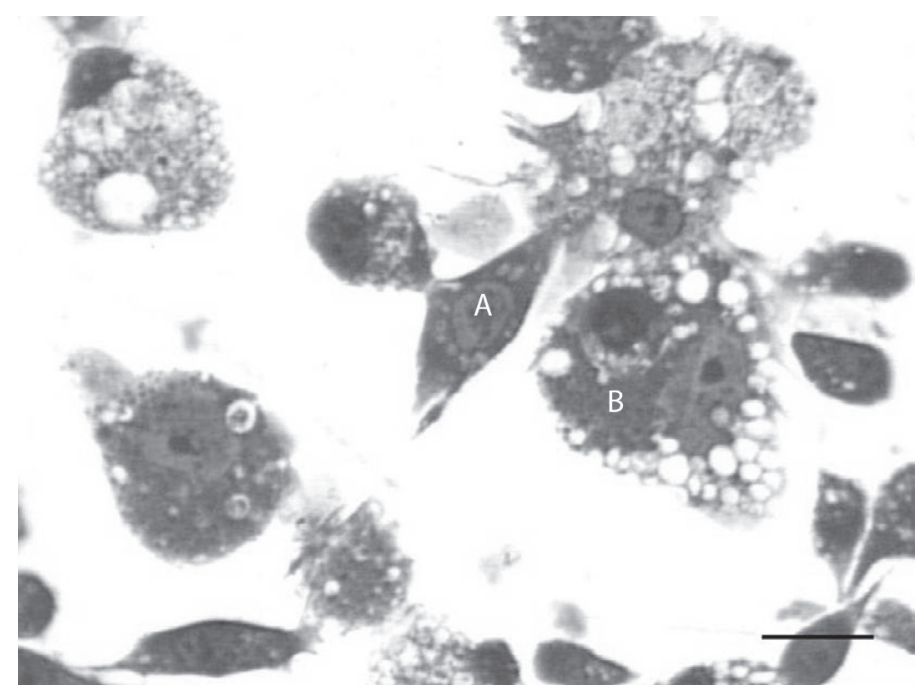

Fig. 1. (A) Célula con apariencia fibroblastoide en un cultivo celular de $A$. aegypti. (B) Célula con apariencia epitelioide en un cultivo celular de A. aegypti. Tinción con Azul de toluidina. (bar: $10 \mu \mathrm{m}$ ).

Fig. 1. (A) Cell with fibroblastoid appearance in a cell culture of A. aegypti. (B) Cell with epitelioid appearance in an A. aegypti's cell culture. Stained with toluidine Blue. (bar: $10 \mu \mathrm{m}$ ).

\section{CUADRO 1}

Promedio del tamaño celular en cultivos celulares de A. aegypti

TABLE 1

Average of the cellular size in cell cultures of A. aegypti

$\begin{array}{lcccc}\text { Células } & \text { Parámetros } & \mathrm{N} & \text { Promedio }(\mu \mathrm{m})^{*} & \text { Error estándar } \\ \text { Apariencia fibroblastoide } & \text { Largo } & 30 & 10.84 \pm 2.54 & \pm 0.46 \\ & \text { Ancho } & 30 & 5.31 \pm 1.26 & \pm 0.23 \\ \text { Apariencia epitelioide } & \text { Largo } & 30 & 23.04 \pm 4.00 & \pm 0.73 \\ & \text { Ancho } & 30 & 13.96 \pm 3.70 & \pm 0.67\end{array}$

$*=$ Promedio \pm desviación estándar. 
Citoquímica: Con relación a la reacción de PAS, se evidenció un $7.08 \%$ de células con gránulos PAS positivo infectadas con L. panamensis (Cuadro 2). La Fig. 2A muestra una célula de $A$. aegypti, con gránulos color magenta en su citoplasma, característico de la coloración de PAS positivo, evidenciando posiblemente la presencia de carbohidratos, principalmente glucógeno y mucinas. Además, se observó un 50.93\% de células infectadas con vacuolas que contenían un material que fue positivo a la coloración de PAS, en un ámbito de reacción de débil a fuerte (Fig. 2B). La técnica de la DAB fue negativa para la detección de peroxidasas.

En el Cuadro 2 se observa el porcentaje de células con gránulos PAS positivo, así, como el porcentaje de células con vacuolas que contenían un material que fue positivo a la coloración de PAS, infectadas con el parásito.

Infección celular: La observación de los cultivos celulares de $A$. aegypti infectados con L. panamensis, evidenció la presencia de formas amastigotas al interior de vacuolas parasitóforas durante los días 3, 6 y 9 post-infección (Fig. 3). En la Fig. 4 se observó que en el día 6 (18.90\%), se presentó el mayor porcentaje de infección con relación a los días $3(14.06 \%)$ y $9(15.59 \%)$, pero no se encontraron diferencias significativas según la prueba de Anova (Tukey, $\mathrm{p}=0.5$ ).
En el Cuadro 3 se observan los datos obtenidos del proceso de infección de la línea celular de A. aegypti con L. panamensis. Sólo el porcentaje de promastigotes por células presentó diferencias significativas (Tukey, $\mathrm{p}<0.05$ ) en el día 3 con relación a los días 6 y 9 según la prueba de Anova.

\section{Microscopia electrónica de transmisión:} Ultraestructuralmente se identificó en las células del cultivo, con y sin infección, la presencia de organelos característicos tales como: núcleo, mitocondrias, vacuolas y lisosomas. Las células de cultivos celulares sin infectar, presentaron un núcleo voluminoso, con poca cromatina condensada que ocupaba la mitad del citoplasma, el cual tenía un aspecto de panal; además se observó la presencia de vacuolas con y sin material fibrilar (Fig. 5A). En las células infectadas, se evidenció la presencia de formas promastigotas en el interior del citoplasma. Igualmente, se logró observar vacuolas con y sin material fibrilar. El núcleo se encontró más al extremo de las células y en la mayoría de observaciones éste se identificó muy eucromático (Fig. 5B). Desde el punto de vista ultraestructural y de citoquímica, se puede sugerir la presencia tanto de lisosomas como de vacuolas con contenido enzimático asociado con carbohidratos.

CUADRO 2

Promedio de células con gránulos PAS positivo y el promedio de células con vacuolas PAS positivo, en cultivos celulares de A. aegypti infectados con L. panamensis

TABLE 2

Average of cells with PAS positive grains and the average of cells with PAS positive vacuols, in cell cultures of A. aegypti infected with L. panamensis

$\begin{array}{lccc}\text { Parámetros } & \text { Células/campo } & \text { Promedio (\%) } & \text { Error estándar } \\ \text { Gránulos PAS + } & 113 & 7.08 \pm 2.73 & \pm 0.25 \% \\ \text { Vacuolas PAS + } & 108 & 50.93 \pm 5.2 & \pm 0.50 \% \\ *=\text { Promedio } \pm \text { desviación estándar. } & & \end{array}$




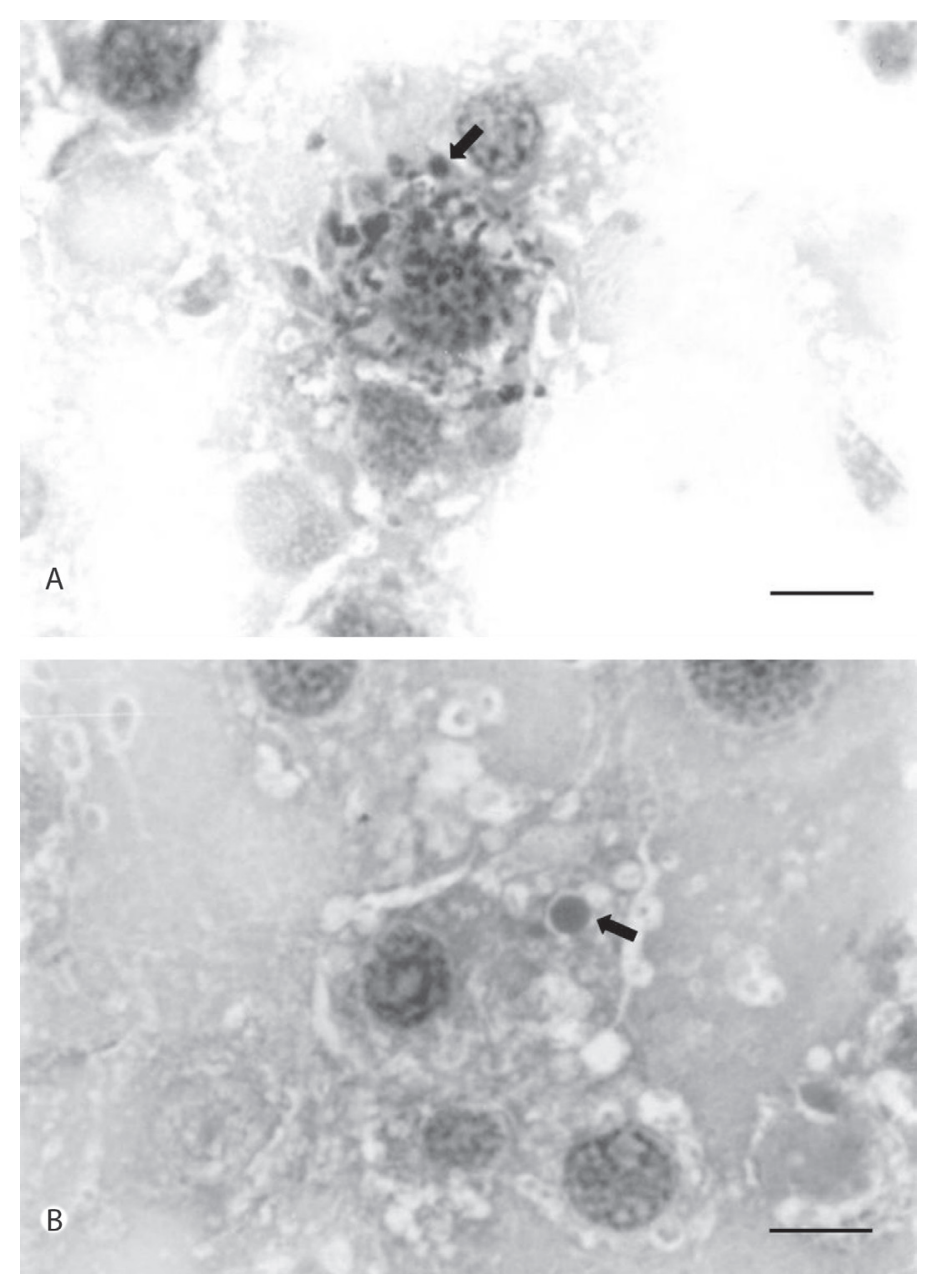

Fig. 2. (A) Célula de cultivo celular de A. aegypti con gránulos PAS positivo, infectada con L. panamensis (flecha). (B) Célula de cultivo celular de A. aegypti, con vacuola PAS positivo, infectada con L. panamensis (flecha). (bar: $10 \mu \mathrm{m}$ ).

Fig. 2. (A) Cell of $A$. aegypti's cell culture with PAS positive grains, infected with $L$. panamensis (arrow). (B) Cell of A. aegypti's cellular culture, with PAS positive vacuole, L. panamensis (arrow). (bar: $10 \mu \mathrm{m}$ ).

\section{DISCUSIÓN}

La presencia de dos grupos diferentes de células en los cultivos celulares derivados del mosquito $A$. aegypti se debe, posiblemente, a los diversos tipos de tejidos disponibles, a partir de huevos embrionados utilizados durante la formación de los cultivos primarios (Charpentier et al. 1995, Rey et al. 2000). Sin embargo, predominaron las formas de apariencia epitelioides, como lo registró Ardila et al. (2005), diferente a lo observado en las líneas celulares Mos. 20 y 29, derivadas de tejidos larvarios de $A$. aegypti que presentaron una morfología en su mayoría fibroblastoide (Varma y Pudney 1969, Ardila et al. 2005).

Las vacuolas que fueron apreciadas en las electromicrografías, son similares a las 


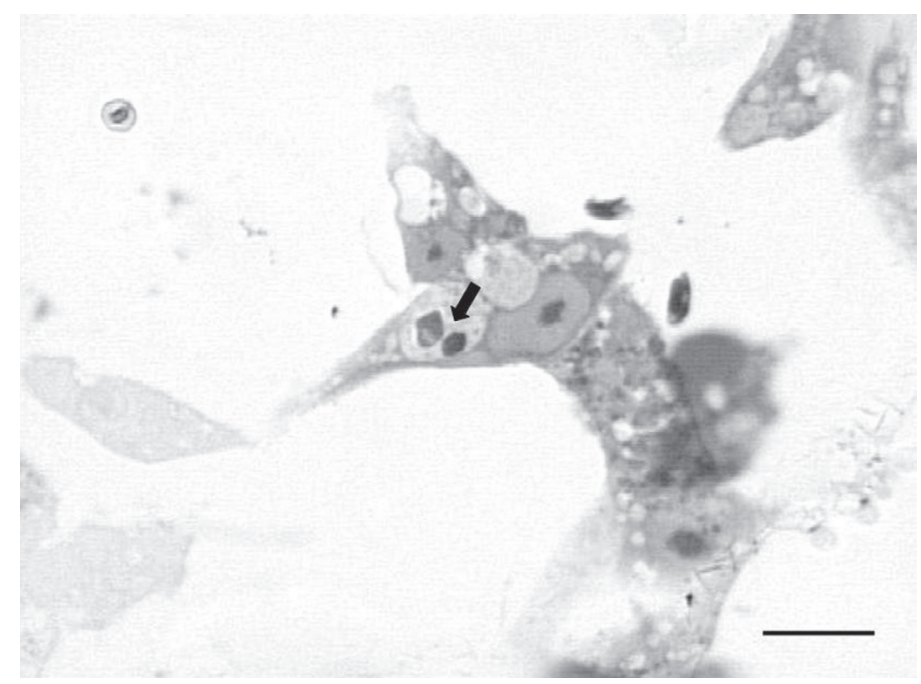

Fig. 3. Células de A. aegypti con dos amastigotes de L. panamensis, día 3 postinfección (flecha). (bar: $10 \mu \mathrm{m})$.

Fig. 3. Cells of A. aegypti with two amastigotes of L. panamensis, day 3 postinfection (arrow). (bar: $10 \mu \mathrm{m}$ ).

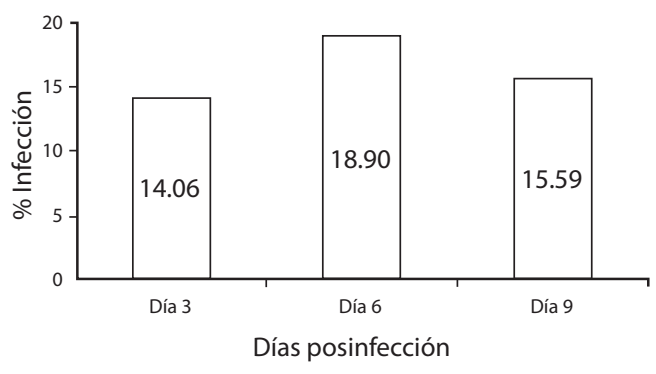

Fig. 4. Porcentaje de infección de células de $A$. aegypti infectadas con L. panamensis, los días 3, 6 y 9 postinfección.

Fig. 4. Percentage of infection of $A$. aegypti infected cells with L. panamensis, days 3, 6 and 9 post-infection.

observadas en el citoplasma de una línea celular de A. triseriatus (Charpentier et al. 1995). El resultado positivo a la coloración de PAS concuerda con lo descrito en una línea celular de $A$. eucalypti, en donde se menciona la presencia de vesículas densas, las cuales fueron PAS positivo. Estas vesículas fueron descritas como semejantes a lisosomas, aclarando que su naturaleza y función precisa no se habían determinado (Grace 1971). La evidencia ultraestructural obtenida en el presente trabajo, indica que efectivamente corresponden a lisosomas y su reacción positiva a la coloración de PAS, lo reafirma. En cuanto a la presencia del material PAS positivo, con diferente grado de intensidad, dentro de la gran cantidad de vacuolas citoplasmáticas y gránulos, creemos que puede deberse a acumulación de productos derivados del metabolismo celular.

Es importante resaltar que $A$. aegypti no es vector de Leishmania, pero si de otras infecciones que afectan a los animales y al hombre; entre estas tenemos: dengue, fiebre amarilla y filariasis (Brito et al. 1999, Harrington et al. 2005). No obstante, líneas celulares derivadas de mosquitos han sido utilizadas como posibles modelos in vitro para el establecimiento y aislamiento de algunos patógenos, que no están necesariamente relacionados con sus hospederos naturales. Son ilustrativos al respecto, los ejemplos siguientes: en 1973 Buckley demostró la capacidad del Toxoplasma gondii de sobrevivir en tres líneas celulares de Aedes ( $A$. albopictus, A. aegypti y A. w-albus). Mazzola 

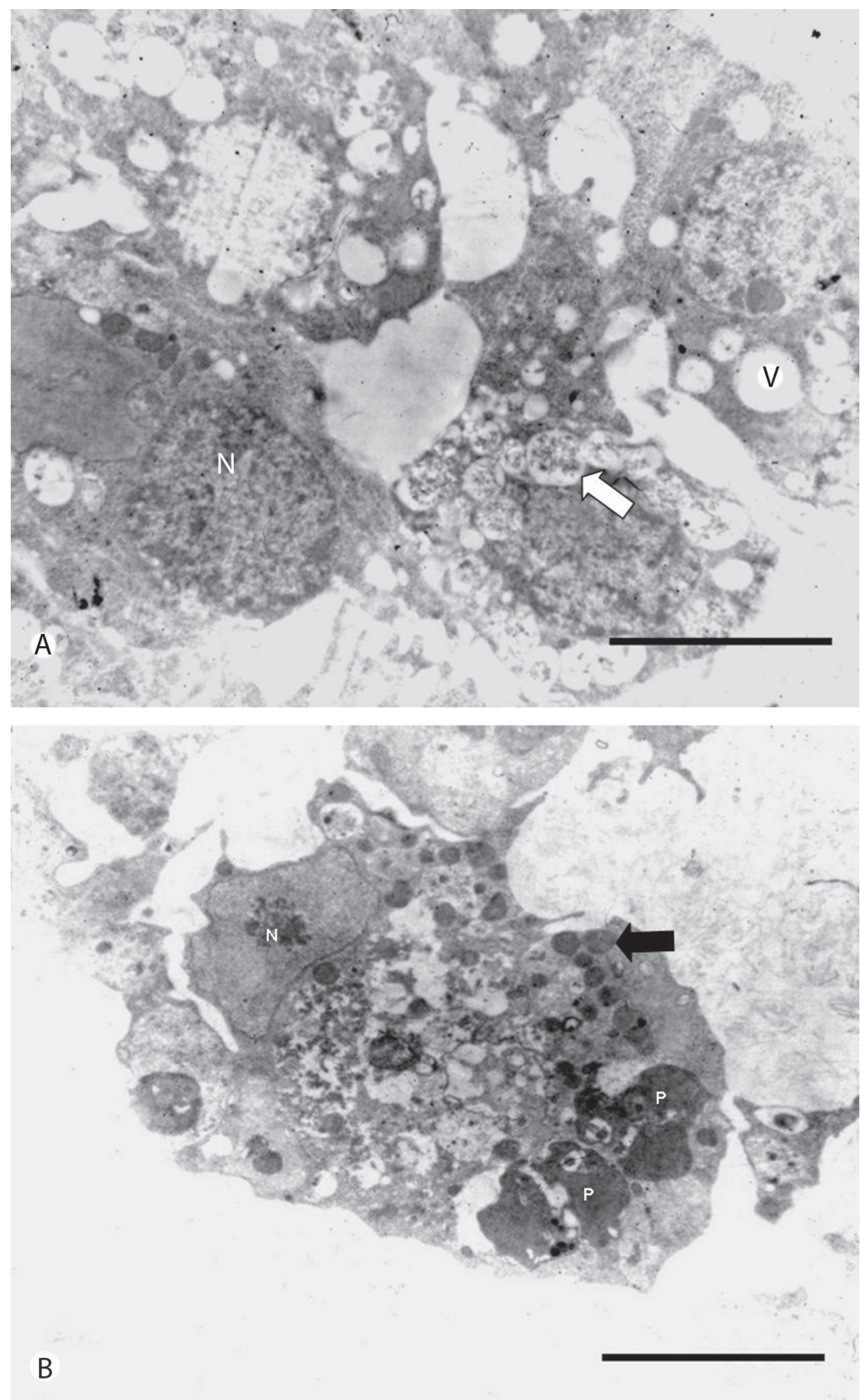

Fig. 5. Electromicrografías de células del cultivo celular de A. aegypti. (A) Células sin infectar, presentando vacuolas vacías (V) y con material fibrilar (flecha blanca). (B) Célula infectada con promastigotes $(\mathrm{P})$ de L. panamensis, día 3 post-infección. Núcleo celular $(\mathrm{N})$. Lisosomas (flecha negra). (bar: $6 \mu \mathrm{m}$ ).

Fig. 5. Electron-micrographs of cells from A. aegypti's cell culture. (A) Noninfected cells, presenting empty vacuoles (V) and vacuoles with fibrilar material (white arrow). (B) Cell infected with promastigotes $(\mathrm{P})$ of L. panamensis, day 3 post-infection. Nucleus $(\mathrm{N})$. Lysosomes (black arrow). (bar: $6 \mu \mathrm{m}$ ). 
CUADRO 3

Promedio de datos obtenidos durante el proceso de infección

TABLE 3

Average of data collected during the infection process

$\begin{array}{cccccc}\text { Día } & \begin{array}{c}\% \\ \text { Infección* }\end{array} & \begin{array}{c}\text { Amastigotes } \\ \text { /célula* }\end{array} & \begin{array}{c}\text { Amastigotes } \\ \text { /célula* }\end{array} & \begin{array}{c}\% \\ \text { Promastigotes/ } \\ \text { en contacto* }\end{array} & \begin{array}{c}\text { Promastigotes/ } \\ \text { en contacto* }\end{array} \\ 3 & 14.06 \pm 9.60 & 18.23 \pm 15.66 & 1.17 \pm 0.26 & 12.63 \pm 2.60 & 1.24 \pm 0.43 \\ 6 & 18.90 \pm 5.99 & 15.13 \pm 5.98 & 1.40 \pm 0.73 & 7.17 \pm 3.91 & 0.85 \pm 0.37 \\ 9 & 15.59 \pm 4.43 & 13.03 \pm 4.40 & 1.25 \pm 0.28 & 6.52 \pm 2.59 & 1.08 \pm 0.16\end{array}$

* $=$ Promedio \pm Desviación estándar.

et al. (1976, 1979), realizaron la infección de células de A. albopictus con Anaplasma marginale, en donde se observaron eritrocitos infectados con el parásito, fagocitados por las células de $A$. albopictus, así como formas libres del parásito, en el citoplasma de éstas. En el 2006 Horta et al., reportaron el aislamiento y establecimiento de Rickettsia felis en la línea celular C6/36 de A. albopictus. Estudios realizados por Dedet y Gaudin (1977), reportan la capacidad de internalización y transformación del parásito $L$. donovani en cultivos celulares derivados del mosquito A. albopictus, logrando así su infección.

En el presente trabajo se demostró que las formas promastigotas de $L$. panamensis tienen la capacidad de transformarse en amastigotes en células derivadas de tejidos embrionarios del mosquito $A$. aegypti; lo anterior, fue también observado con las especies L. chagasi y L. braziliensis en la misma línea celular de mosquito (Muñoz et al. 2005). La adhesión e internalización del parásito en estos cultivos celulares, son debidos probablemente, a la posible actividad endocítica o fagocítica de algunas células del mismo cultivo. Lo cual coincide con los hallazgos registrados en células de origen embrionario de Drosophila, que permitieron detectar ciertos receptores parecidos al de los macrófagos en mamíferos que actúan en la fagocitosis (Echalier 1997).
En el proceso infectivo del parásito en los sustrato celulares derivados de $A$. aegypti, se debe tener en cuenta la presencia de ciertos carbohidratos en la superficie de promastigotes, responsables de la adhesión del parásito con el intestino del flebótomo (Sacks y kamhawi 2001). La forma promastigota de todas las especies de Leishmania sintetizan LPG, considerado el mayor glicoconjugado de superficie en el promastigote (Turco y Descoteaux 1992). Una de las funciones de esta molécula es la adhesión del parásito al epitelio intestinal del vector (Muskus y Marin 2002). También, es posible que la afinidad del parásito con células derivadas de los mosquitos, pueda estar relacionada con sistemas ligando- receptor conservados en insectos (Muñoz et al. 2005).

Los porcentajes de infección hallados en los días 3, 6 y 9 postinfección, en este estudio, fueron mayores a los observados en cultivos celulares de $A$. aegypti infectados con L. chagasi, pero menores en comparación a los infectados con L. braziliensis (Muñoz et al. 2005). Estas diferencias tal vez sean debidas, al polimorfismo del LPG entre especies de Leishmania, lo cual ha demostrado que en condiciones in vivo, estas moléculas intervienen en la capacidad de adhesión del parásito con el intestino del vector (Pimenta et al. 1994). Por otro lado, el posible éxito de la infección en las células de $A$. aegyp$t i$, se debe parcialmente a que la temperatura 
$\left(26^{\circ} \mathrm{C}\right)$ es óptima para el mantenimiento de los cultivos y simultáneamente para los promastigotes de Leishmania (Zilberstein y Shapira 1994, Muñoz et al. 2005).

Con los hallazgos observados en este trabajo por microscopia de luz y electrónica se confirmó la internalización y transformación del parásito, demostrando la capacidad que tiene las células de este cultivo celular de ser infectadas por L. panamensis, lo cual permitiría proponer a este cultivo celular como un posible modelo in vitro para el estudio de la interacción parásito-vector.

\section{AGRADECIMIENTOS}

A Manuel Guillermo Forero por sus conocimientos y capacitaciones para el manejo del software ImageJ. A Cesar Augusto Díaz, por el apoyo brindado para el procesamiento de los resultados. A Andrés Ramírez, por el manejo y mantenimiento de los cultivos celulares y los parásitos. A Colciencias y al Instituto Nacional de Salud por la financiación del joven investigador Alfonso Arturo Miranda H. A la Universidad de La Salle, a la Universidad del Rosario y Colciencias por la financiación del presente trabajo.

\section{RESUMEN}

La primera línea celular de Aedes aegypti fue establecida por Grace en 1966 y desde entonces se han utilizado para el estudio de virus, bacterias y parásitos. En el presente trabajo se describen, por primera vez, algunas características citoquímicas de los cultivos celulares de $A$. aegypti, infectados con la cepa (MHOM/CO/87CL412) de Leishmania panamensis. También se realizó un estudio morfológico de las células del cultivo. Se observaron 30 células pequeñas con apariencia fibrolastoide de $10.84 \pm 2.54 \mu \mathrm{m}$ de largo y $5.31 \pm 1.26 \mu \mathrm{m}$ de ancho; otras 30 presentaron apariencia epitelioide con $23.04 \pm 4.00 \mu \mathrm{m}$ de largo y $13.96 \pm 3.70 \mu \mathrm{m}$ de ancho; éstas últimas predominaron sobre las de apariencia fibroblastoide. De 113 células, un 7.08\%, presentaron abundantes gránulos citoplasmáticos positivos con la coloración de PAS, indicando presencia de polisacáridos. La prueba de peroxidasa dio un resultado negativo. El mayor porcentaje de infección $(18.90 \%)$, de un total de 101 células, se presentó el día 6 . Ultraestructuralmente, las células presentaron un citoplasma con aspecto vacuolado; algunas contenían parásitos, otras material fibrilar y otras estaban vacías. Los resultados indican que los cultivos celulares de $A$. aegypti pueden ser infectados por L. panamensis y mantener dicho proceso por aproximadamente una semana.

Palabras clave: ácido periódico schiff, cultivos celulares, Aedes aegypti, Leishmania panamensis, microscopia electrónica de transmisión.

\section{REFERENCIAS}

Ardila, A., J. Escovar \& F. Bello. 2005. Características de nuevos cultivos celulares derivados de tejidos embrionarios de Aedes aegypti (Diptera: Culicidae). Biomédica 25: 65-75.

Bello, F.J., A.J. Mejia, M.P. Corena, M. Ayala, L. Sarmiento, C. Zuniga \& M.T. Palau. 2005. Experimental infection of Leishmania (L.) chagasi in a cell line derived from Lutzomyia longipalpis (Diptera:Psychodidae). Mem. Inst. Oswaldo Cruz 100: 519-525.

Berens, R.L. \& J.J. Marr. 1979. Growth of Leishmania donovani amastigotes in a continuous macrophagelike cell culture. J. Protozool. 26: 453-456.

Bhat, U.K. \& K.R. Singh. 1969. Structure and development of vesicles in larval tissue culture of Aedes aegypti (L.). J. Med. Entomol. 6: 71-74.

Brito, A.C., G. Fontes, E.M. Rocha, D.A. Rocha \& L. Regis. 1999. Development of Dirofilaria immitis (Leidy) in Aedes aegypti (L.) and Culex quinquefasciatus (say) from Maceio, Alagoas, Brazil. Mem. Inst. Oswaldo Cruz 94: 575-576.

Buckley, S.M. 1973. Survival of Toxoplasma gondii in mosquito cell lines and establishment of continuous infection in Vero cell cultures. Exp. Parasitol. 33: 23-26.

Charpentier, G., S. Belloncik, G. Ducros, D. Fontenille, L.Tian \& J.M. Quiot. 1995. Establishment and characterization of three cell lines from Aedes triseriatus (Diptera: Culicidae). J. Med. Entomol. 32: 793-800.

Dedet, J.P. \& O.G. Gaudin. 1977. Leishmania donovani multiplication in a cell line of Aedes albopictus. Trans. R. Soc. Trop. Med. Hyg. 70: 535-536.

Dobson, S.L., E.J. Marsland, Z. Veneti, K Bourtzis \& S.L. O'Neill. 2002. Characterization of Wolbachia host cell range via the in vitro establishment of infections. Appl. Environ. Microbiol. 68: 656-660.

Echalier, G. 1997. Drosophila Cells in Culture. Academic, Nueva York, EEUU. 
Fampa, P., M.S. Correa-da-Silva, D.C. Lima, S.M. Oliveira, M.C. Motta \& E.M. Saraiva. 2003. Interaction of insect trypanosomatids with mosquitoes, sand fly and the respective insect cell lines. Int. J. Parasitol. 33: 1019-1026.

García del Moral, R. 1993. El laboratorio de Anatomía Patológica. Interamericana, McGraw-Hill, Madrid, España.

Grace, T.D.C. 1962. Establishment of four strains of cells from insect tissue grown in vitro. Nature 195: 788-789.

Grace, T.D.C. 1966. Establishment of a line of mosquito (Aedes aegypti L.) cells grown in vitro. Nature 211: 366-367.

Grace, T.D.C. 1971. The morphology and physiology of cultured invertebrate cells, p. 171-208. In C. Vago (ed.). Invertebrate Tissue Culture Vol. 1. Academic, Nueva York, EEUU.

Harrington, L.C., T.W. Scott, K. Lerdthusnee, R.C. Coleman, A. Costero, G.G. Clark, J.J. Jones, S. Kitthawee, P. Kittayapong, R. Sithiprasasna \& J.D. Edman. 2005. Dispersal of the dengue vector Aedes aegypti within and between rural communities. Am. J. Trop. Med. Hyg. 72: 209-220.

Horta, M.C., M.B. Labruna, E.L. Durigon \& T.T. Schumaker. 2006. Isolation of Rickettsia felis in the mosquito cell line C6/36. Appl. Environ. Microbiol. 72: $1705-1707$.

Kaminsky, R., E. Beaudoin \& I. Cunningham. 1987. Studies on the development of metacyclic Trypanosoma brucei sspp. cultivated at $27{ }^{\circ} \mathrm{C}$ with insect cell lines. J Protozool. 34: 372-377.

Lynn, D.E. 2001. Novel techniques to establish new insect cell lines. In Vitro Cell Dev. Biol. Anim. 37: 319-321.

Lynn, D.E. 2002. Methods for maintaining insect cell cultures. J. Insect Sci. 2: 9.

Mazzola, V., T.E. Amerault \& T.O. Roby. 1976. Survival of Anaplasma marginale in Aedes albopictus cells. Am. J. Vet. Res. 37: 987-989.

Mazzola, V., T.E. Amerault \& T.O. Roby. 1979. Electron microscope studies of Anaplasma marginale in an Aedes albopictus culture system. Am. J. Vet. Res. 40: 1812-1815.

Miranda, A., W. Serrano, M. Ayala \& F. Bello. 2005. Evaluación del proceso infectivo de Leishmania
Chagasi en la línea celular lulo, con base en variables ambientales y fisicoquímicas. Rev. Med. Vet. 10: 23-38.

Muñoz, C.C., A. Barreto \& F. Bello. 2005. Análisis de la susceptibilidad de una línea celular de Aedes aegypti (Diptera: Culicidae) a la infección con Leishmania (L) chagasi y Leishmania (V) braziliensis. Rev. Cienc. Salud 3: 119-128.

Muskus, C.E. \& V.M. Marin. 2002. Metacyclogenesis: a basic process in the biology of Leishmania. Biomédica 22: 167-177.

Pimenta, P.F., E.M. Saraiva, E. Rowton, G.B. Modi, L.A. Garraway, S.M. Beverley, S.J. Turco \& D.L. Sacks. 1994. Evidence that the vectorial competence of phlebotomine sand flies for different species of Leishmania is controlled by structural polymorphisms in the surface lipophosphoglycan. Proc. Natl. Acad. Sci. U.S.A. 91: 9155-9159.

Rey, G., C. Ferro \& F. Bello. 2000. Establishment and Characterization of a New Continuous Cell Line from Lutzomyia longipalpis (Diptera: Psychodidae) and its Susceptibility to Infections with Arboviruses and Leishmania chagasi. Mem. Inst. Oswaldo Cruz 95: 103-110.

Sacks, D. \& S. Kamhawi. 2001. Molecular aspects of parasite-vector and vector-host interactions in leishmaniasis. Annu. Rev. Microbiol. 55: 453-483.

Sarmiento, L., M. Ayala, S. Peña, G. Rodríguez, Z. Fermín \& F. Tapia. 2006. Estudio ultraestructural de la fagocitosis de promastigotes y amastigotes de Leishmania mexicana por la línea de células dendríticas FSDC. Biomédica 26: 17-25.

Singh, K.R. 1972. Growth of arboviruses in arthropod tissue culture. Adv. Virus Res. 17: 187-206.

Sudeep, A.B., D.T. Mourya \& A.C. Mishra. 2005. Insect cell culture in research: Indian scenario. Indian $\mathrm{J}$. Med. Res. 121: 725-738.

Syafruddin, A., R. Kamimura \& F. Kawamoto 1992. Development of Plasmodium berghei ookinetes to young oocysts in vitro. J. Protozool. 39: 333-338.

Turco, S.J. \& A. Descoteaux. 1992. The lipophosphoglycan of Leishmania parasites. Annu. Rev. Microbiol. 46: 65-94.

Varma, M.G. \& M. Pudney. 1969. The growth and serial passage of cell lines from Aedes aegypti (L.) larvae in different media. J. Med. Entomol. 6: 432-439. 
Zapata, L.A.C., C.E. Cardenas \& F. Bello. 2005. Characterization of cell cultures derived from Lutzomyia spinicrassa (Diptera: Psychodidae) and their susceptibility to infection with Leishmania (Viannia) braziliensis. Med. Sci. Monit. BR 11: 457-464.

Zilberstein, D. \& M. Shapira. 1994. The Role of $\mathrm{pH}$ and Temperature in the Development of Leishmania Parasites. Annu. Rev. Microbiol. 48: 449-470.
Zuluaga, M. \& S.M. Robledo. 2004. Las células de Langerhans en la inmunidad a leishmaniasis. Biomedica 24: 302-317.

\section{REFERENCIA DE INTERNET}

Rasband, W.S. 1997. ImageJ. U.S. National Institutes of Health, Bethesda, Maryland, USA. (Consultado: 1 febrero 2006, http://rsb.info.nih.gov/ij/). 